Journal of Computer Science 3 (7): 465-477, 2007

ISSN 1549-3636

(C) 2007 Science Publications

\title{
Artificial Intelligence Based Three-Phase Unified Power Quality Conditioner
}

\author{
Moleykutty George \\ Lecturer, Faculty of Engineering and Technology, Multimedia University \\ Melaka Campus, 75450 Melaka, Malaysia
}

\begin{abstract}
Power quality is an important measure of the performance of an electrical power system. This paper discusses the topology, control strategies using artificial intelligent based controllers and the performance of a unified power quality conditioner for power quality improvement. UPQC is an integration of shunt and series compensation to limit the harmonic contamination within $5 \%$, the limit imposed by IEEE-519 standard. The novelty of this paper lies in the application of neural network control algorithms such as model reference control and Nonlinear AutoregressiveMoving Average (NARMA)-L2 control to generate switching signals for the series compensator of the UPQC system. The entire system has been modeled using MATLAB 7.0 toolbox. Simulation results demonstrate the applicability of MRC and NARMA-L2 controllers for the control of UPQC.
\end{abstract}

Key words: APF, MRC, NARMA-L2, VSI, DVR

\section{INTRODUCTION}

The better controllability, higher efficiency, higher current carrying capability, and fast switching characteristics of static power converters are promoting major changes in controlling the power flow of transmission and distribution systems. On the other hand the nonlinear characteristics of these switching devices introduce many undesirable features such as low power factor, poor voltage regulation, zerosequence currents, imbalances, and harmonics. Traditionally passive filters, synchronous condensers, capacitors, and phase advancers were used to improve the power quality. The undesirable features such as lower efficiency, bulkiness, fixed compensation, resonance, and electromagnetic interference of traditional compensators urged power electronics and power system engineers to develop an adjustable and dynamic solution for power quality problems. Active power filters (APF) were introduced in order to compensate reactive power, to cancel current harmonics, to correct current imbalances and to control zero-sequence currents $^{[1]-[12]}$, where as the disturbances in terminal voltages shall be compensated using dynamic voltage restorer $(\mathrm{DVR})^{[13]-[17]}$. More recently UPQC has been introduced as a one shot solution to improve power quality. A multilevel converter using diode-clamped inverters that can handle higher voltages with extra degrees of freedom in the form of redundant voltage states has been proposed in ${ }^{[18]}$. A new topology and control circuit proposed in ${ }^{[19]}$ has been successfully tested for various operating conditions. $\operatorname{In}^{[20]}$ authors have identified and tested new functionalities such as elimination of voltage sags resulted from short circuits. A new methodology for the evaluation and control of losses taking place in a UPQC has been proposed in ${ }^{[21]}$. A new control strategy aimed to compensate reactive power, negative sequence current, current harmonics and also to regulate any voltage imbalance has been proposed in $^{[22]}$. A neural network controlled UPQC without injection transformer has been designed and reported in ${ }^{[23]}$. Another control structure ${ }^{[24]}$ using linear quadratic regulator (LQR) along with hysteresis control is successfully tested for various operating conditions. UPQC implemented in ${ }^{[25]}$ uses a control circuit without reference calculation. Complicated control structures of UPQC ${ }^{[17]-[25]}$ have been replaced by a simple control technique in $^{[26]}$. Voltage interruption can also be eliminated by the use of a unified power quality conditioner with distributed generation ${ }^{[27]}$. Recent research shows that AI based controllers are very promising in the field power system and power electronics ${ }^{[28]-[49]}$. $\mathrm{In}^{[29]}$ and ${ }^{[34]}$ the conventional PI controller is replaced by a fuzzy logic controller [FLC] for the determination of the reference current in a shunt active power filter. Reference ${ }^{[32]}$ shows the successful application of FLC to generate the switching signals required in an active filter realized using current controlled PWM inverter. $\mathrm{In}^{[37]}$, T-S fuzzy model is used to predict future harmonic compensating current in an APF system. Successful application of artificial neural network (ANN) controllers for the implementation of APF system has been reported ${ }^{[38]-[47]}$ and many disadvantages of conventional controllers could be eliminated by the use of ANN controllers.

In this paper UPQC has been proposed for the cancellation of harmonic currents, to compensate reactive power, to eliminate voltage harmonics, to improve voltage regulation, to correct voltage and current imbalances and to avoid voltage interruption.

Corresponding Author: Moleykutty George, Lecturer, Faculty of Engineering and Technology, Multimedia University, Melaka Campus, 75450 Melaka, Malaysia 
The novelty of this paper lies in the application of NNC algorithms such as MRC, and NARMA- L2 control to generate switching signals for the series compensator of the UPQC system. The control strategies of UPQC are detailed in second part of this paper. Simulation results in the third part illustrate the successful implementation of UPQC using NARMA-L2 and MRC.

\section{UPQC WITH INTELLIGENT CONTROLLERS}

Principle of UPQC: UPQC is one of the custom power devices used at the electrical power distribution systems to improve the power quality of distribution system customers. UPQC could be used to cancel current harmonics, to compensate reactive power, to eliminate voltage harmonics, to improve voltage regulation, to correct voltage and current imbalances, to correct voltage sag or swell and to avoid voltage interruptions. A UPQC consists of both shunt and series compensators. A shunt compensator is used to cancel the disturbances in current whereas series compensator is used to cancel disturbances in voltage. Shunt compensator could be connected to the left or right of the series compensator. Ideally, shunt compensator injects current to achieve purely balanced sinusoidal source currents in phase with the supply voltages at rated magnitude and frequency. On the other hand series compensation is used to inject voltage to maintain terminal voltage at rated magnitude and frequency.

Control circuit of UPQC: A three-phase system has been selected to study the performance of the UPQC system. (Fig. 1) shows the schematic diagram of the UPQC system. Voltage source inverters are used for shunt and series compensation. One may note that both voltage source inverters are supplied from a common dc link capacitor. One of the voltage source inverters is connected in parallel with the a.c. system while the other one is connected in series with the a.c. system through injection transformers. The inverter connected in parallel, together with its control circuit forms the shunt compensation circuit. On the other hand the inverter connected in series with appropriate control circuit forms the series compensation circuit. For the successful operation of the UPQC, the dc capacitor voltage should be at least $150 \%$ of maximum line-line supply voltage. To regulate the capacitor voltage constant, either a PI controller or a fuzzy controller could be used. Thus the control structure of UPQC has been divided into shunt compensator and series compensator control circuits.

Shunt compensation control circuit: A current controlled VSI connected in parallel to the source through booster inductors functions as the shunt compensator. (Fig. 2) shows the block diagram of the control circuit of the shunt compensator ${ }^{[11]}$. The control circuit consists of a voltage control loop and two current control loops. The ideal requirements of the shunt compensator circuit are (i) to maintain the capacitor voltage at a constant steady value and (ii) to maintain the source current purely sinusoidal in nature and in phase with the supply voltage.

a) Voltage control loop: The voltage control loop is used to determine the amplitude of the reference source current. Under steady state conditions the d.c. load removes energy from capacitor at constant average rate and the capacitor voltage can be maintained constant only if the incoming power from the a.c. side is equal to the output power demand. Thus the variation in capacitor voltage is a measure of the amplitude of the reference current. The voltage control loop senses the voltage across the capacitor, increases the current drawn from the supply if the capacitor voltage tends to decrease from the reference value and decreases the current drawn from the ac side when the capacitor voltage tends to increase. Thus the voltage control loop monitors the output voltage and determines the amplitude of the source current. The amplitude of the reference source current could be evaluated as follows:

$$
I_{\max }=G_{C}\left(V_{d c r}-V_{d c}\right)
$$

where $G_{C}$ represents a PI or fuzzy controller.

Implementation Using PI Controller: According to stability criteria, the following relations may be used to determine the value of $K_{p}$ and $K i$ and of the PI controller.

$$
\begin{aligned}
I_{s} & \leq \frac{C_{D} V_{d c r}}{3 K_{P} L_{s}} \\
I_{s} & \leq \frac{K_{p} V \cos \phi}{2 R_{s} K_{p}+L_{s} K_{i}}
\end{aligned}
$$

$$
\text { where } \begin{array}{lll}
V & - & \text { supply voltage/ phase }(\mathrm{V}) \\
V_{d c r} & - & \text { reference dc voltage }(\mathrm{V}) \\
C_{D} & - & \text { dc link capacitor value }(\mathrm{F}) \\
R_{s} & - & \text { source resistance }(\Omega) \\
L_{s} & - & \text { source inductance }(\mathrm{H}) \\
\cos \phi & - & \text { source power factor } \\
I_{s} & - & \text { supply line current }(\mathrm{A})
\end{array}
$$

With these stability limits satisfied, the PI controller will maintain the capacitor voltage at the constant 


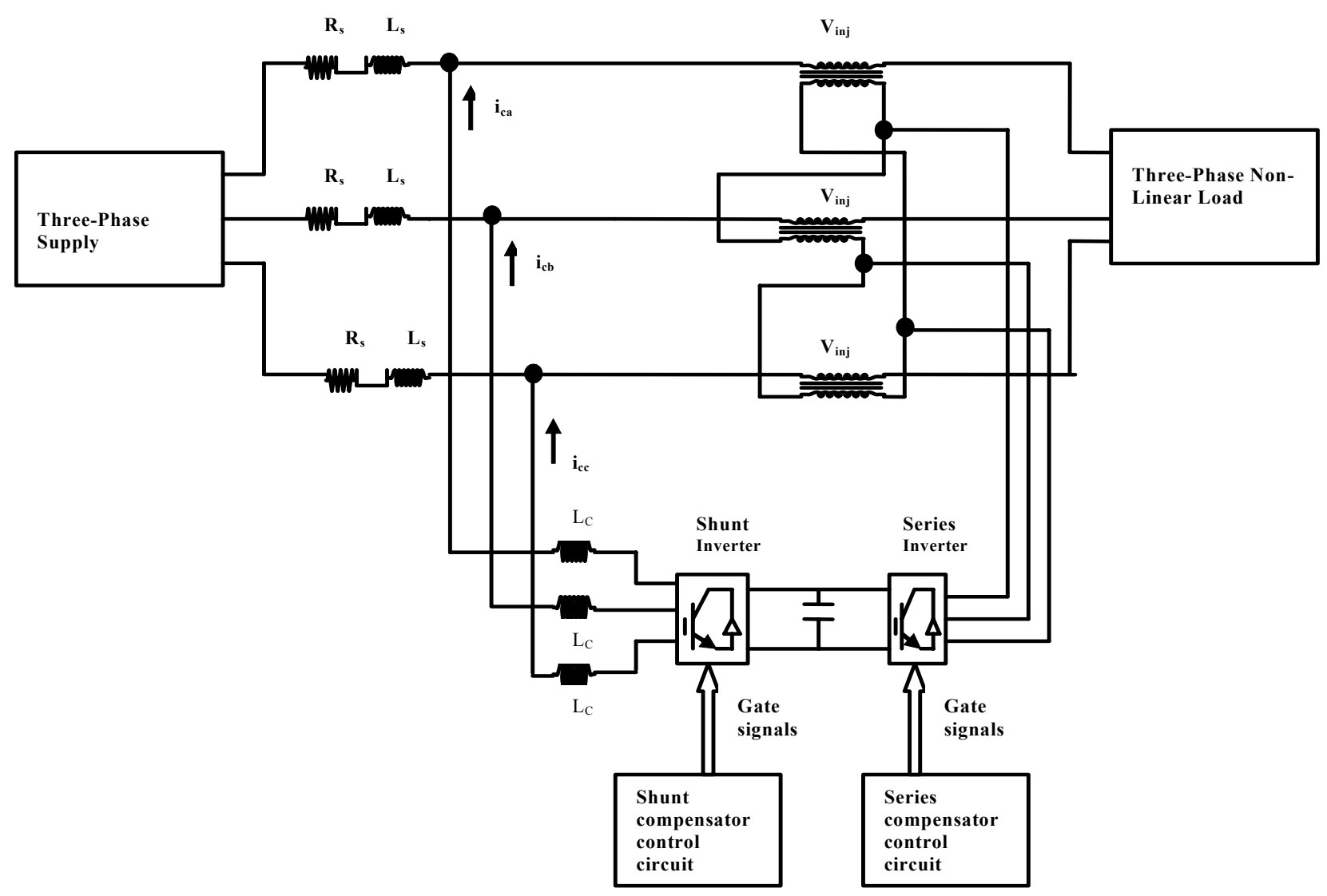

Fig. 1: Schematic diagram of a UPQC

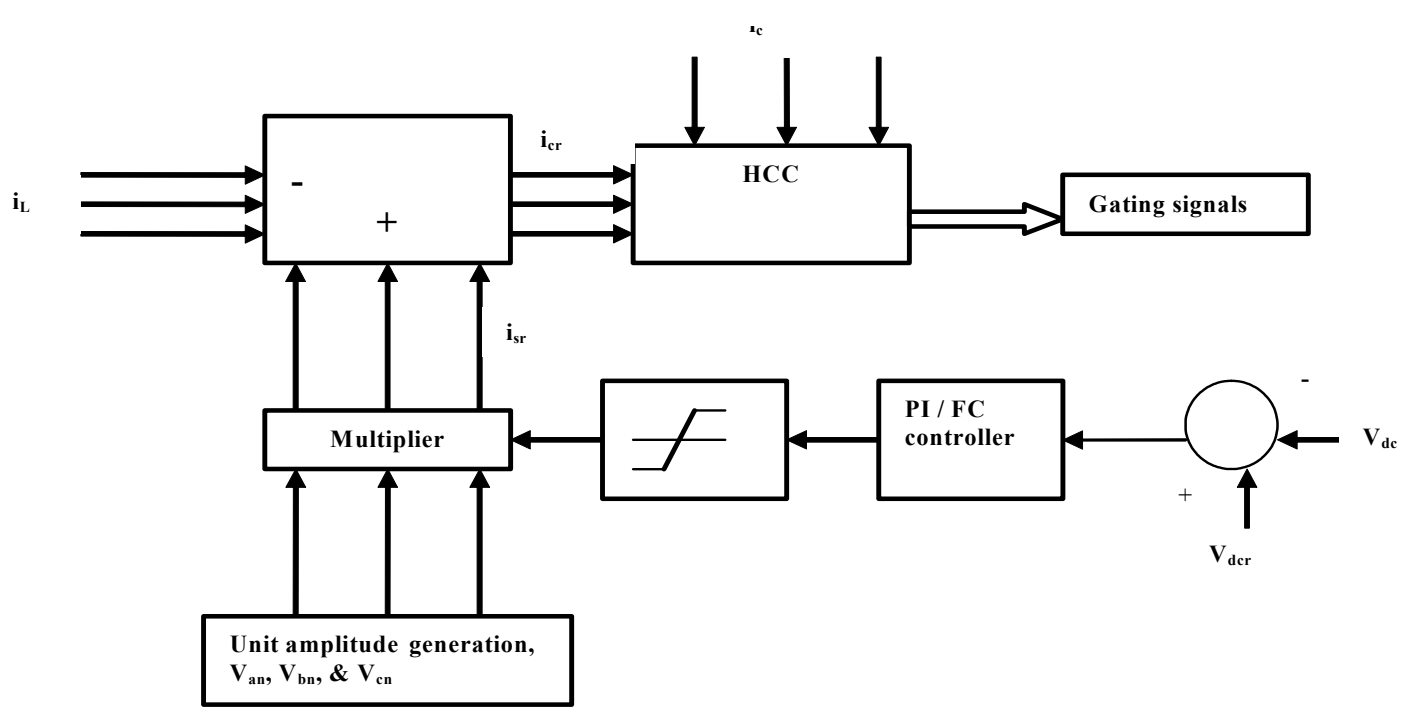

Fig.2: Shunt compensator control circuit 
reference value and the output of the PI controller is in fact a measure of the amplitude of the reference supply current.

Implementation Using Fuzzy Logic Controller: A fuzzy logic controller uses linguistic variables instead of numerical variables. The internal structure of FLC is shown in (Fig. 3). Fuzzy inference process mainly consists of three steps namely fuzzification of the input variables, determination of the membership function (MF) graph for the output variable, and finally defuzzification of the linguistic output variable.

(i) Fuzzification of the input variables: In the fuzzification stage numerical values of the variables are converted into linguistic variables. Seven linguistic variables namely NB (negative big), NM (negative medium), NS (negative small), ZE (zero), PS (positive small), PM (positive medium), and PB (positive big) are assigned for each of the input variables and output variable. Normalized values are used for fuzzy implementation. As there are seven variables for inputs and output there are $7 \times 7=49$ input output possibilities as tabulated in Table. 1. A membership function value between zero and one will be assigned to each of the numerical values in the membership function graph. The membership function graph can have different shapes triangular, trapezoidal or gauzzian etc. For simplicity triangular membership function graph is chosen for the system under study.

(ii) Determination of the MF graph for the output variable: Consider the situation with error in capacitor voltage (e) equals 0.2 per unit and change in error (ce) 0.6 per unit. $\mathrm{e}=0.2$ per unit is having a membership function value of 0.1 in the $\mathrm{ZE}$ membership function curve and 0.6 in the PM membership function graph. The change in error 0.6 per unit has a membership function value of 1 in the PS curve. With e in the ZE membership function curve and ce in the PM curve will be in the PM membership function curve as indicated in Table. 1. Application of Mamdani implication method will result in a degree of fulfillment equals the minimum of 0.1 and 1 which is equal to 0.1 as shown in (Fig. 4(a)).

Similarly when e equals PS and ce equals PM then $\delta I_{m}$ equals $\mathrm{PM}$ and will have a degree of fulfillment of 0.6 as shown in (Fig. 4(b)). The union of the above two output MF graphs (Fig. 4(a)) and (Fig. 4(b)) gives the final MF graph for the output as shown in (Fig. 4(c)).

iii) Defuzzification of the linguistic output variable: In the defuzzification stage the fuzzy output will be converted into a numerical value. Mean of maxima method (MOM) is used for defuzzification. In the MOM the highest membership function value of 0.6 is selected. Selecting three different points will give a final numerical output value of

$$
\delta I_{\max }=\sum_{m=1}^{M} \frac{\delta I_{\max m}}{M}=\frac{0.7}{3}+\frac{1}{3}+\frac{1.75}{3}=1.15
$$

Thus when $\mathrm{e}=0.2$ p.u. and ce $=0.6, \delta I_{\max }$ equals 1.15 p.u.. Thus output of the fuzzy controller gives the change in reference current $\delta I_{\max }(n)$ at the nth sampling time. The peak reference current $I_{\max }(n)$ at the $\mathrm{n}^{\text {th }}$ sampling time is determined by adding the previous reference current $I_{\max }(n-1)$ to the calculated change in reference current:

$I_{\text {max }}(n)=I_{\text {max }}(n-1)+\delta I_{\text {max }}(n)$

In classical control theory this is an integration effect.

Table 1: Control rule table

\begin{tabular}{|c|c|c|c|c|c|c|c|c|}
\hline & & & & Error & (e) & & & \\
\hline \multirow{8}{*}{$\begin{array}{l}\text { Change } \\
\text { in error } \\
\text { (ce) }\end{array}$} & & NB & NM & NS & $\mathrm{ZE}$ & PS & $\mathrm{PM}$ & PB \\
\hline & NB & NB & NB & NB & NB & NM & NS & ZE \\
\hline & $\mathrm{NM}$ & NB & NB & NB & $\mathrm{NM}$ & NS & ZE & PS \\
\hline & NS & NB & NB & NM & NS & ZE & PS & PM \\
\hline & ZE & NB & $\mathrm{NM}$ & NS & $\mathrm{ZE}$ & PS & PM & PB \\
\hline & PS & NM & NS & ZE & PS & PM & PB & PB \\
\hline & $\mathrm{PM}$ & NS & ZE & PS & $\mathrm{PM}$ & PB & PB & PB \\
\hline & PB & ZE & PS & PM & PB & PB & PB & PB \\
\hline
\end{tabular}

b) Current control loops: Ideally, shunt compensation is used to achieve a purely sinusoidal current wave form in phase with the supply voltage. The voltage control loop cannot ask the shunt compensation control circuit to draw the required power at an arbitrary current wave shape. It is the current control loop that makes sure that the supply current has the desired shape and amplitude as commanded by the voltage control loop.

Estimation of reference current templates: A phase locked loop (PLL) could be used to generate a unit amplitude wave form in phase with the supply voltage. The reference source current is obtained by multiplying the amplitude determined by the voltage control loop with the unit amplitude waveform generated by the PLL. The difference between the instantaneous source and load currents gives the reference compensation currents.

Hysteresis current controller: A hysteresis current controller $[\mathrm{HCC}]$ is used to generate switching pulses required for the VSI. In a hysteresis controller the reference compensation current is compared with the actual current that is being injected by the compensation circuit. A positive pulse is produced if the actual current tends to decrease below the lower 


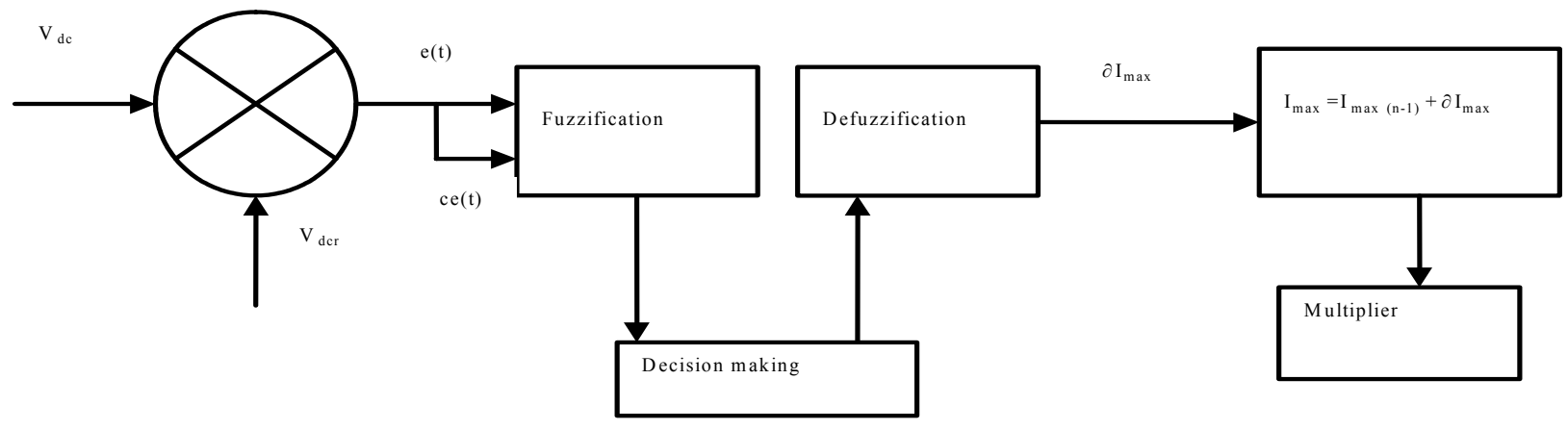

Fig. 3: Internal Structure of the Fuzzy Logic Controller

(a)
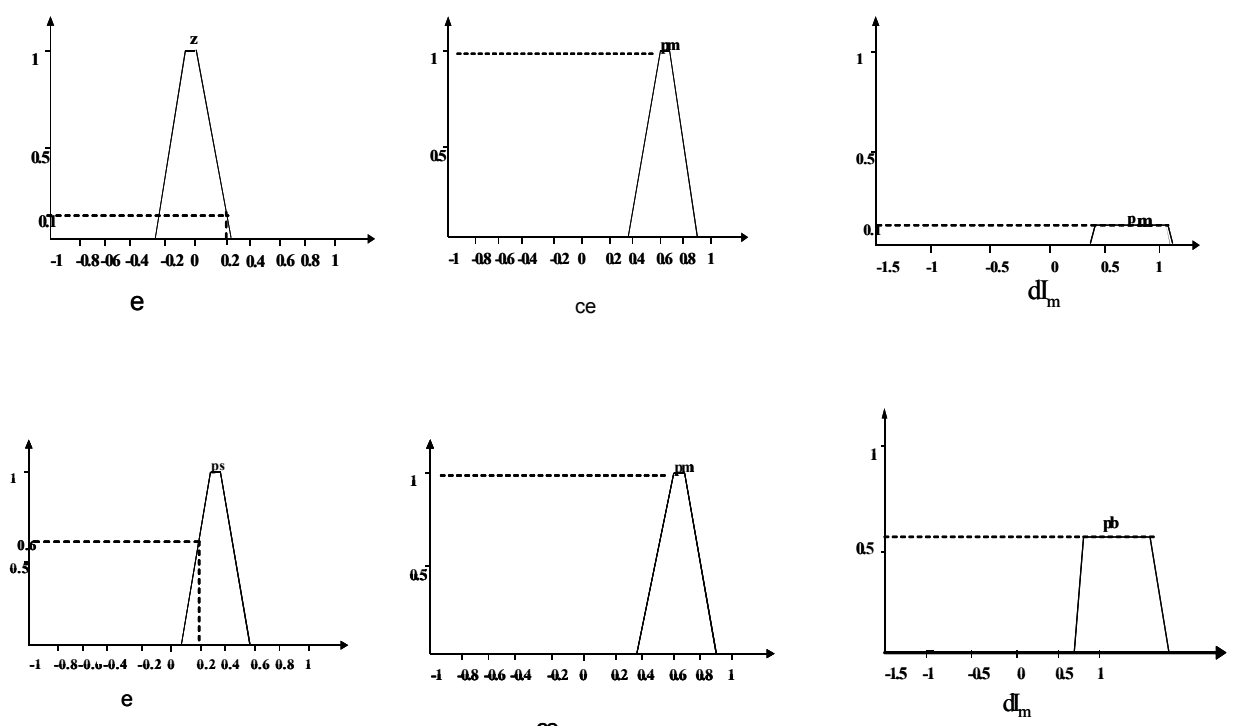

(b)

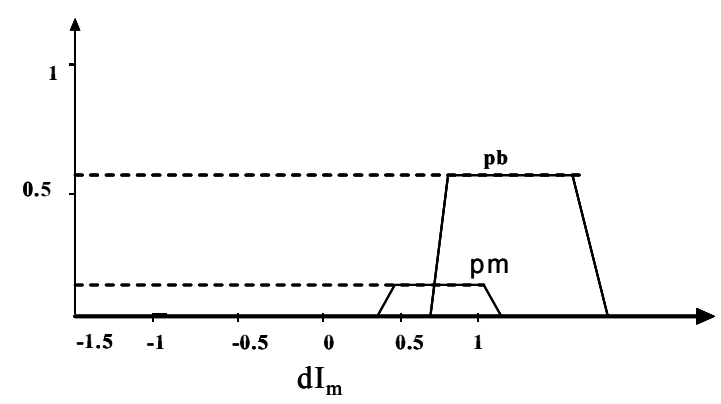

(c)

Fig. 4: Information processing in fuzzy systems.

(a) Rule 1. (b) Rule 2. (c) Output MF graph 
hysteresis limit, while a negative pulse is produced if the current exceeds the upper hysteresis limit. Thus in a hysteresis current controller the actual compensation current is forced to stay within a particular hysteresis band.

\section{2) Series compensation control circuit:}

a) Conventional Techniques: A DVR based on a pulse-width modulated (PWM) VSI, which is capable of generating or absorbing real and reactive power independently at its ac output terminals is used as the series compensator. The series compensator injects three single-phase ac voltages in series and in synchronism with the upstream voltages in the distribution system. The power circuit could be divided into two main parts: three-phase VSI, three single-phase injection transformers. The three single-phase transformers are connected to the distribution system with a star/open winding. The star/open winding allows the injection of positive, negative and zero sequence voltages. The windings on the inverter side are connected in delta through inductors to provide high voltage. The block diagram of a series compensator is shown in (Fig. 5). Using Park's transformation actual receiving end voltages $\left(\mathrm{V}_{\mathrm{ra}}, \mathrm{V}_{\mathrm{rb}}\right.$, and $\left.\mathrm{V}_{\mathrm{rc}}\right)$ may be decomposed into stationary axes as follows:

$$
V_{d}=\sqrt{\frac{2}{3}}\left(V_{r a} \operatorname{Cos} \theta+V_{r b} \operatorname{Cos}\left(\theta-120^{\circ}\right)+V_{r c} \operatorname{Cos}\left(\theta-240^{\circ}\right)\right)
$$

$$
V_{q}=-\sqrt{\frac{2}{3}}\left(V_{r a} \operatorname{Sin} \theta+V_{r b} \operatorname{Sin}\left(\theta-120^{\circ}\right)+V_{r c} \operatorname{Sin}\left(\theta-240^{\circ}\right)\right)
$$$$
V_{0}=\sqrt{\frac{2}{3}}\left(\frac{1}{\sqrt{2}} V_{r a}+\frac{1}{\sqrt{2}} V_{r b}+\frac{1}{\sqrt{2}} V_{r c}\right)
$$

It has been found that to obtain line-line voltages of $400 \mathrm{~V}, \mathrm{~V}_{\text {dref }}=400 \mathrm{~V} ; \mathrm{V}_{\text {qref }}=0 \mathrm{~V} ; \& \mathrm{~V}_{\text {oref }}=0 \mathrm{~V}$. PWM technique is used to generate switching patterns for the VSI's. Using abc to dq0 and dq0 to abc transformation, the receiving end voltage is regulated at $400 \mathrm{~V} \mathrm{rms}$ by means of a PI controller.

b) Neural network control algorithms: The learning ability, self-adapting, and super-fast computing features of ANN controllers make it well suited for the control of power electronic circuits. In learning process, neural network adjusts its structure such that it will be able to follow the supervisor. The learning is repeated until the difference between network output and the supervisor is low.

Multilayer neural network controllers such as
NARMA-L2 control ${ }^{[48]}$ and MRC $^{[49]}$ have been successfully applied in the identification and control of dynamic systems. There are typically two steps involved when using neural networks for control: system identification and control design. In the system identification stage, a neural network model of the plant that is to be controlled is developed. In the control design stage, the developed neural network plant model is used to the train the controller. The system identification stage is the same for both controllers. The control design stage, however, is different for each of the architectures.

In this paper the control circuit of the series compensator shown in (Fig. 5) has been replaced by NARMA-L2 and MRC controllers and simulation was carried out using MATLAB/ Neural network blockset/control systems/NARMA-L2 and MATLAB/ Neural network blockset/control systems/MRC. The data obtained from the series compensator shown in (Fig. 5) is used to train NARMA-L2 and MRC controllers. It has been observed that the implementation of MRC is more complex than that of NARMA-L2 controller for the same output performance.

System Identification Stage: The first phase of plant identification process is to generate input/ output data to train a neural network to represent the forward dynamics of the plant. This could be achieved by either generating the training data from simulink plant model or by importing the training data from a valid data file with input and output values. The LevenbergMarquadrat algorithm is used for training the plant model. Once the training data is acceptable a neural network could be trained to identify the function of the plant identification model described as:

$$
\begin{aligned}
& y(k+d)=N[y(k), y(k-1), . ., y(k-n+1), \\
& u(k), u(k-1), . ., u(k-n+1)]
\end{aligned}
$$

where $u(k)$ is the system input, $y(k)$ is the system output and $d$ is the system delay.

To determine the control input that causes the plant output to follow a specific reference, the controller could be identified using the expression

$$
\begin{aligned}
& u(k)= \\
& \frac{y_{r}(k+d)-f\left[\begin{array}{l}
y(k), y(k-1), . ., y(k-n+1), u(k-1), . ., \\
u(k-m+1)
\end{array}\right]}{g[y(k), y(k-1), . . y(k-n+1), u(k-1), . u(k-m+1)]}(9)
\end{aligned}
$$




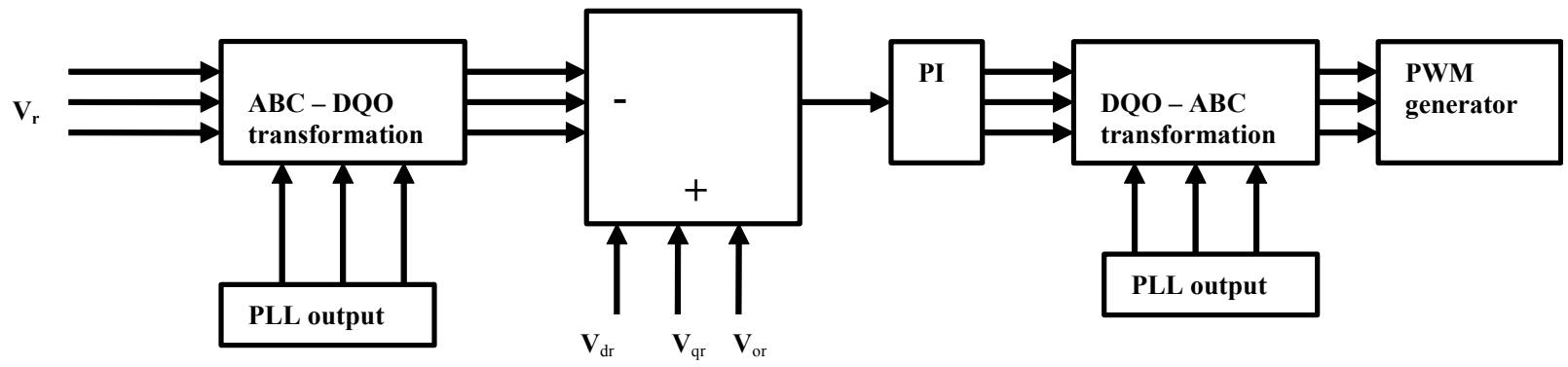

Fig. 5: Series Compensator Control Circuit

However determination of the control input based on the output at the same time is not realistic and

$$
\begin{aligned}
& y(k+d)=f[y(k), y(k-1), . .(y(k-n+1), \\
& u(k), u(k-1) \ldots u(k-n+1)]+ \\
& g[y(k), \ldots y(k-n+1), u(k) \ldots u(k-n+1)] . u(k+1)
\end{aligned}
$$

And the controller is then given by the following equation

$$
\begin{gathered}
u(k+1)= \\
\frac{y_{r}(k+d)-f\left[\begin{array}{l}
y(k), . ., y(k-n+1), u(k), . ., \\
u(k-n+1)
\end{array}\right]}{g[y(k), . ., y(k-n+1), u(k), . . u(k-m+1)]}
\end{gathered}
$$

(Fig. 6) shows the block diagram representation of the system identification stage. The plant model predicts future plant outputs. The plant model has only one hidden layer.

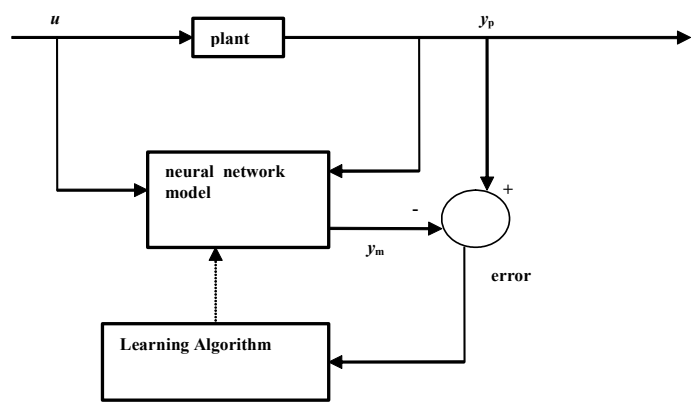

Fig. 6: System Identification

NARMA-L2 controller: (Fig. 7) is the block diagram representation of NARMA-L2 controller. NARMA-L2 controller requires less computation compared with MRC. The controller is simply a rearrangement of the plant model. This controller could be identified with the hence uses the model

previously identified neural network plant model. The main idea of this type of control is to transform nonlinear system dynamics by canceling the nonlinearities.

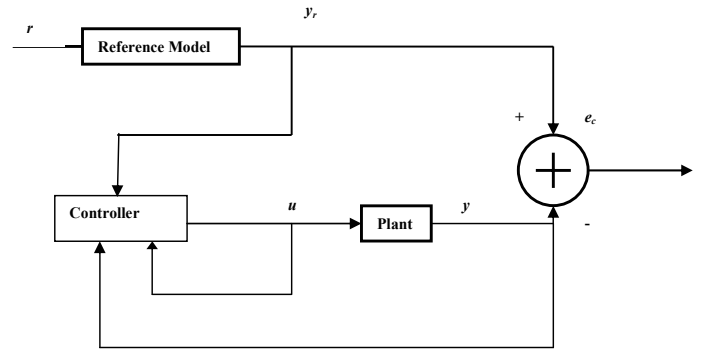

Fig. 7: NARMA-L2 Controller

Unlike the NARMA-L2 controller, model reference controller uses two neural networks: a plant model network and a controller network. To train the controller, first of all a neural network plant model has to be identified and trained as in NARMA-L2 controller, following that training data has to be generated using either a simulink reference model or by importing data from a MATLAB file. (Fig.8) is the block diagram representation of the model reference controller. Plant identification stage is the same as that of NARMA-L2 controller. The Levenberg-Marquadrat algorithm is used for training the neural network plant model. Following the plant identification stage the controller should be trained so that $\mathrm{NN}$ plant model output follows $\mathrm{NN}$ reference model output. The controller training is computationally expensive and time consuming as it requires dynamic back propagation. The BFGS (Broyden, Fletcher, Goldfarb, and Shanno) training algorithm was used to train the controller. 
Model reference controller: As MRC requires a separate a controller network and dynamic back propagation algorithm is used to train the controller, the model reference controller training is more time consuming and complex than that of NARMA-L2 controller.

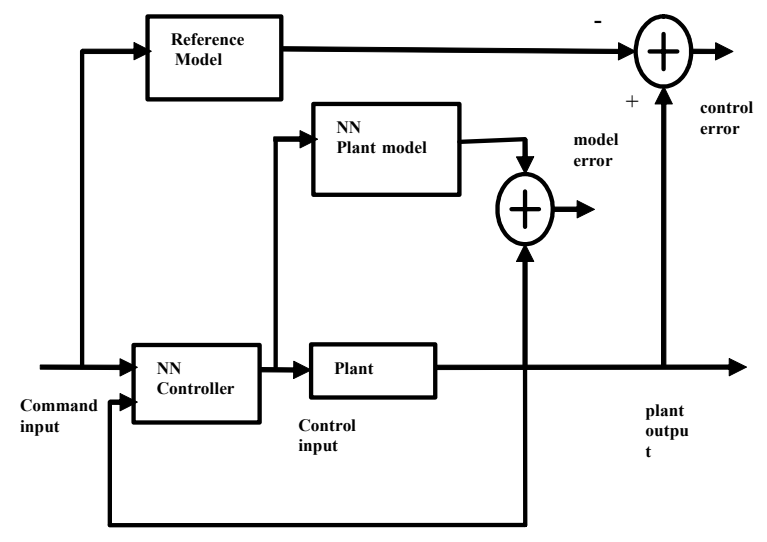

Fig. 8: Model Reference Controller

Design Parameters of UPQC System: The design values of the developed UPQC system are as follows: Supply voltage $\quad-\quad 400 \mathrm{~V}$ (rms, line-toline)

DC Voltage

DC Link Capacitor

Booster inductance $\quad-\quad 500 \mu \mathrm{H}$

- $\quad 750 \mathrm{~V}$

$500 \mathrm{~V} / 2,000 \mathrm{~V}, \mathrm{Y} / \Delta$

\section{SIMULATION RESULTS}

Using MATLAB 7.0 toolbox the entire UPQC system has been modeled. The shunt compensator control circuit has been implemented using PI and FLC to regulate the capacitor voltage and HCC to generate switching signals, whereas series compensator is independently controlled using conventional and neural network controllers. The performance of the UPQC system has been analyzed using combination of conventional and ANN controllers in the shunt and series control circuits. The validity of the system for control applications such as voltage and current harmonic eliminations, reactive power compensation, voltage regulation, control of negative and zero sequence components voltage and current, elimination of voltage interruption under short circuit condition has been examined. Simulation results are detailed in the following sub-sections. Simulation results clearly illustrate the successful application of neural network controllers for the implementation of UPQC. Timing details of UPQC are tabulated in Table. 2.
Table 2: UPQC timing

\begin{tabular}{lllll}
\hline Time (s) & $0-0.1$ & $0.1-0.2$ & $0.2-0.3$ & $0.3-0.4$ \\
\hline DVR & OFF & OFF & ON & ON \\
APF & OFF & ON & OFF & ON \\
\hline
\end{tabular}

A. Elimination of Voltage Interruption at the Time of Short Circuit: Ideally utility must maintain rated power at rated magnitude and frequency at consumer terminals. However due to unavoidable short circuit conditions such as single line to ground, line to line, double line to ground faults there can be voltage interruption, negative and zero sequence components etc. The performance of the NARMA-L2 based UPQC has been analyzed with $\mathrm{R}_{\mathrm{la}}=3+\mathrm{j} 240 \Omega$; $\mathrm{R}_{\mathrm{lb}}=20+\mathrm{j} 1.13 \Omega ; \mathrm{R}_{\mathrm{lc}}=15 \Omega$ and by introducing $\mathrm{a}$ single line to ground fault in phase A at $t=0.05 \mathrm{~s}$ at the source side. Analysis of simulation results shown in (Fig. 9), (Fig. 10), and (Fig. 11) indicates that UPQC is able to maintain the terminal voltage at rated magnitude and frequency under short-circuit condition. Both DVR and APF are OFF until $0.05 \mathrm{~s}$. At $\mathrm{t}=0.05 \mathrm{~s}$ due to the short circuit, the source current in phase A increases to a very large value as illustrated in (Fig. 9). From $0.1 \mathrm{~s}$ to $0.2 \mathrm{~s}$ as the APF system is $\mathrm{ON}$ the source currents in phase $\mathrm{B}$ and phase $\mathrm{C}$ also increase. From $0.2 \mathrm{~s}$ to $0.4 \mathrm{~s}$ as the DVR is ON, the receiving end voltage is maintained at rated magnitude and frequency as illustrated in (Fig. 11) and the load currents also reach the expected values as plotted in (Fig. 10).

B. Control of Negative and Zero Sequence Components: The adverse effect of negative and zero sequence components in an unbalanced system could be eliminated by the use of a UPQC system. The performance of the system has been analyzed using MRC with $\mathrm{R}_{\mathrm{la}}=3+\mathrm{j} 240 \Omega ; \mathrm{R}_{\mathrm{lb}}=20+\mathrm{j} 1.13 \Omega$; $\mathrm{R}_{\mathrm{lc}}=15 \Omega$ and the resulting waveforms of source current, load current and receiving end voltage are plotted in figures 12,13 , and 14 respectively. In (Fig. 12), the source currents $i_{\mathrm{sa}}, i_{\mathrm{sb}}$, and $\mathrm{i}_{\mathrm{sc}}$ are balanced sinusoids indicating the successful operation of APF system from $0.1 \mathrm{~s}$ to $0.2 \mathrm{~s}$ and from $0.3 \mathrm{~s}$ to $0.4 \mathrm{~s}$. The DVR system switched ON at $0.2 \mathrm{~s}$ is able to maintain the terminal voltage at rated magnitude and frequency as shown in (Fig. 14).

C. Elimination of Harmonics: The waveform of electrical power generated is purely sinusoidal and free from any distortions. Most of the electrical equipments are designed to operate under pure sinusoidal operating conditions. However the applications of nonlinear loads distort the voltage and current waveforms and these distortions may propagate all over the electrical network results into reduced equipments life, measurement errors, faulty timing signals, maloperation, and overheating etc. Harmonic control and reactive power compensation of static power converters specified in IEEE-519 standard limits the total harmonic distortions (THD) to $5 \%$. The developed UPQC system has been tested for harmonic elimination and reactive power compensation. Simulation results 
shown in (Fig. 15)-(Fig. 19) using conventional controllers with a diode rectifier load clearly indicate the effectiveness of the system to eliminate voltage and current harmonics and to improve the power factor. In (Fig. 15), the source current waveform for phase $\mathrm{A}$ is plotted, whereas the THD of source and load currents are plotted in (Fig. 16).

Table 3: UPQC performance with thyristor rectifier load

\begin{tabular}{lllll}
\hline Controller & $\begin{array}{l}\text { PI - } \\
\text { NARMA-L2 }\end{array}$ & & & \\
$\alpha$ & $5^{\circ}$ & & & \\
& & & & \\
Time (s) & $0-0.1$ & $0.1-0.2$ & $0.2-0.3$ & $0.3-0.4$ \\
$\mathrm{I}_{\text {sthd }}(\%)$ & 75 & 0.18 & 1.2 & 0.6 \\
$\mathrm{I}_{\text {lthd }}(\%)$ & 75 & 75 & 1.2 & 1.1 \\
$\mathrm{I}_{\text {sm }}(\mathrm{A})$ & 0.36 & 137 & 300 & 400 \\
$\mathrm{I}_{\mathrm{lm}}(\mathrm{A})$ & 0.35 & 0.35 & 300 & 285 \\
DPF $_{\text {angle }}{ }^{\circ}$ & -33 & -10 & -13.5 & -17.5 \\
$\mathrm{~V}_{\mathrm{rthd}}(\%)$ & 400 & 300 & 2 & 1.5 \\
$\mathrm{~V}_{\mathrm{rm}}(\mathrm{V})$ & 0.37 & 0.37 & 300 & 290 \\
$\mathrm{~V}_{\mathrm{r} \varphi}{ }^{\circ}$ & 20 & -20 & -12 & -17 \\
\hline
\end{tabular}

Table 4: UPQC performance with thyristor rectifier load

\begin{tabular}{|c|c|c|c|c|}
\hline Controller & $\begin{array}{l}\text { PI - } \\
\text { NARMA-L2 }\end{array}$ & & & \\
\hline$\alpha$ & $20^{\circ}$ & & & \\
\hline Time (s) & $0-0.1$ & $0.1-0.2$ & $0.2-0.3$ & $0.3-0.4$ \\
\hline$I_{\text {sthd }}(\%)$ & 75 & 0.18 & 3.3 & 1.9 \\
\hline $\mathrm{I}_{\text {thd }}(\%)$ & 78 & 70 & 3.3 & 3.5 \\
\hline $\mathrm{I}_{\mathrm{sm}}(\mathrm{A})$ & 0.38 & 137 & 300 & 400 \\
\hline $\mathrm{I}_{\mathrm{Lm}}(\mathrm{A})$ & 0.38 & 0.38 & 300 & 285 \\
\hline DPF $^{2}$ ale ${ }^{\circ}$ & -33 & -10 & -14 & -18 \\
\hline $\mathrm{V}_{\text {rthd }}(\%)$ & 300 & 220 & 5 & 4.5 \\
\hline $\mathrm{V}_{\mathrm{rm}}(\mathrm{V})$ & 5 & 5 & 300 & 290 \\
\hline$V_{\mathrm{r} \varphi}{ }^{\circ}$ & 20 & -20 & -13 & -17 \\
\hline
\end{tabular}

Table 5: UPQC performance with thyristor rectifier load

\begin{tabular}{|c|c|c|c|c|}
\hline Controller & PI - MRC & & & \\
\hline$\alpha$ & $15^{\circ}$ & & & \\
\hline Time (s) & $0-0.1$ & $0.1-0.2$ & $0.2-0.3$ & $0.3-0.4$ \\
\hline $\mathrm{I}_{\text {sthd }}(\%)$ & 75 & 0.18 & 2.35 & 1.33 \\
\hline $\mathrm{I}_{\text {thd }}(\%)$ & 75 & 75 & 2.3 & 2.4 \\
\hline $\mathrm{I}_{\mathrm{sm}}(\mathrm{A})$ & 0.75 & 137 & 300 & 410 \\
\hline $\mathrm{I}_{\mathrm{Lm}}(\mathrm{A})$ & 0.75 & 0.75 & 300 & 285 \\
\hline DPF angle ${ }^{\circ}$ & -33 & -10 & -14 & -18 \\
\hline $\mathrm{V}_{\text {rthd }}(\%)$ & 300 & 300 & 3.6 & 3.2 \\
\hline $\mathrm{V}_{\mathrm{rm}}(\mathrm{V})$ & 4.2 & 4.2 & 300 & 290 \\
\hline $\mathrm{V}_{\mathrm{r} \varphi}^{\circ}$ & 10 & -18 & -13 & -17 \\
\hline
\end{tabular}

Table 6: UPQC performance with diode rectifier load

\begin{tabular}{lllll}
\hline Controller & FLC- Con. & & & \\
\hline Time $(\mathrm{s})$ & $0-0.1$ & $0.1-0.2$ & $0.2-0.3$ & $0.3-0.4$ \\
$\mathrm{I}_{\text {sthd }}(\%)$ & 72 & 0.185 & 1.8 & 1.0 \\
$\mathrm{I}_{\text {Ithd }}(\%)$ & 73 & 73 & 1.8 & 2.2 \\
$\mathrm{I}_{\mathrm{sm}}(\mathrm{A})$ & 0.37 & 137.1 & 285 & 400 \\
$\mathrm{I}_{\mathrm{Lm}}(\mathrm{A})$ & 0.37 & 0.37 & 288 & 280 \\
DPF $_{\text {angle }}{ }^{\circ}$ & -37 & -0.985 & -27 & -27 \\
$\mathrm{~V}_{\text {rthd }}(\%)$ & 73 & 73 & 4 & 4.2 \\
$\mathrm{~V}_{\mathrm{rm}}(\mathrm{V})$ & 0.7 & 0.7 & 330 & 330 \\
$\mathrm{~V}_{\mathrm{r \varphi}}{ }^{0}$ & 10 & -18 & -13 & -17 \\
\hline
\end{tabular}

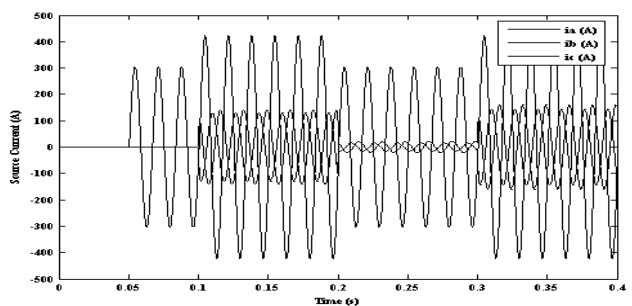

Fig. 9: Source Current (A) with NARMA-L2 Controller

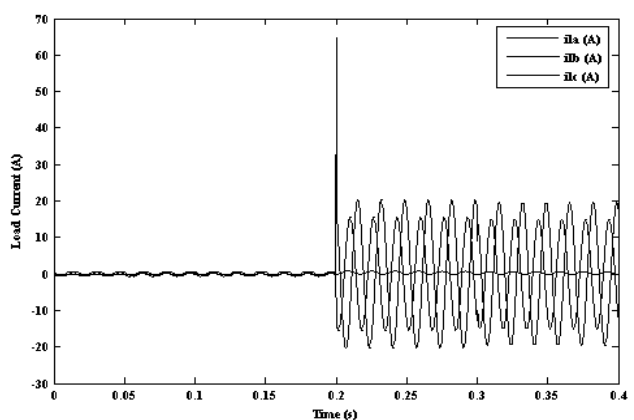

Fig. 10: Load Current (A) with NARMA-L2 Controller

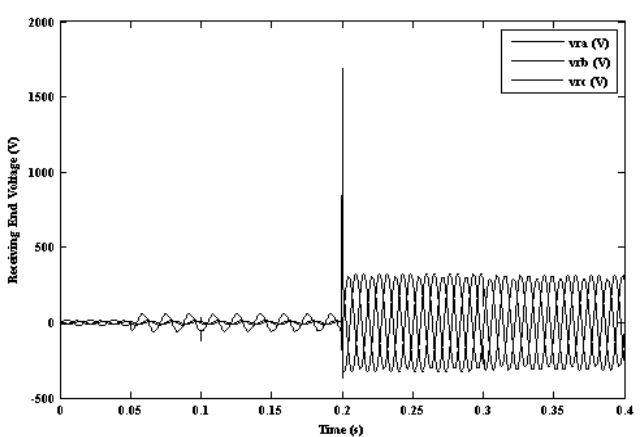

Fig. 11: Receiving End Voltage (V) with NARMAL2 Controller

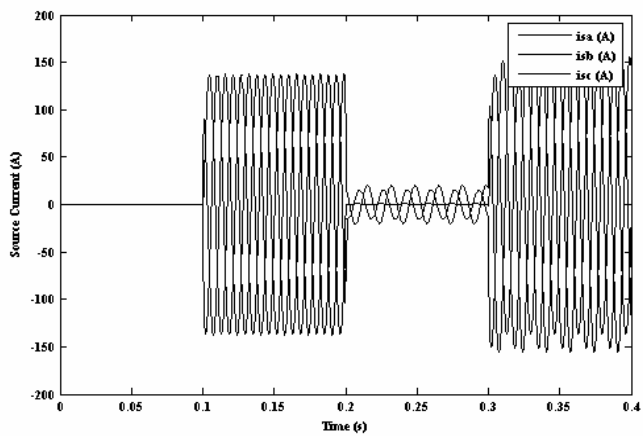

Fig. 12: Source Gurrent (A) with MRC 


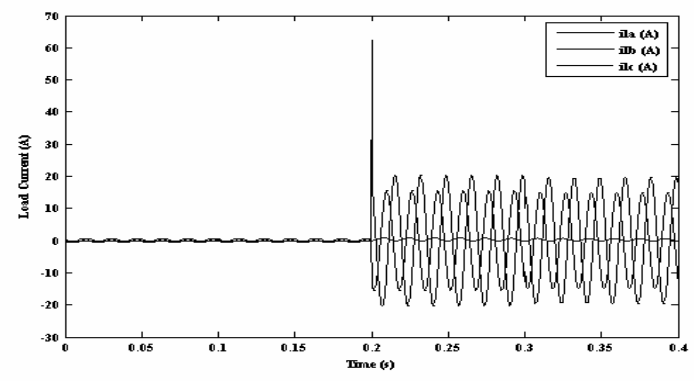

Fig. 13: Load Current (A) with MRC

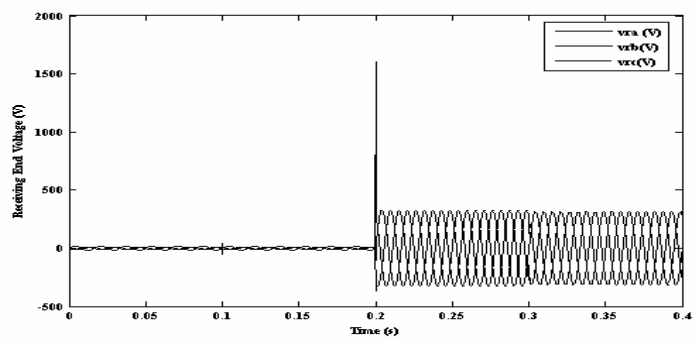

Fig. 14: Receiving End Voltage (V) with MRC

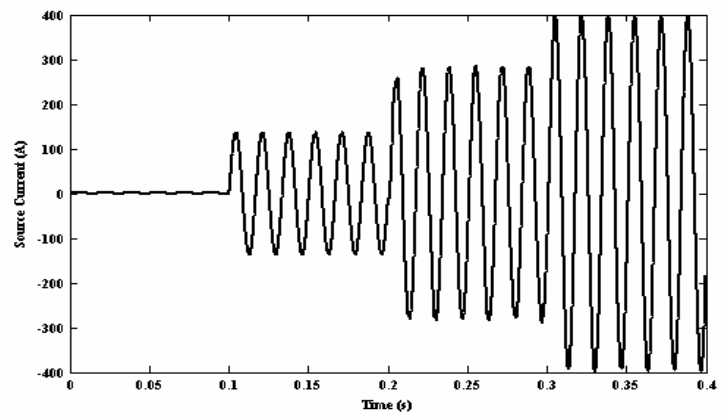

Fig. 15: Source Current (A) with Conventional Controller

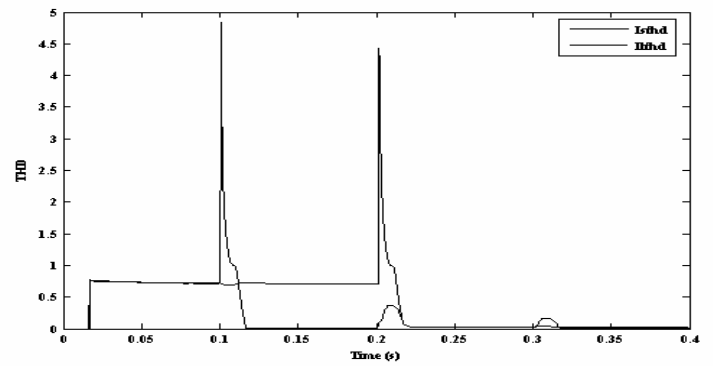

Fig. 16: THD of Source and Load currents with Conventional Controller

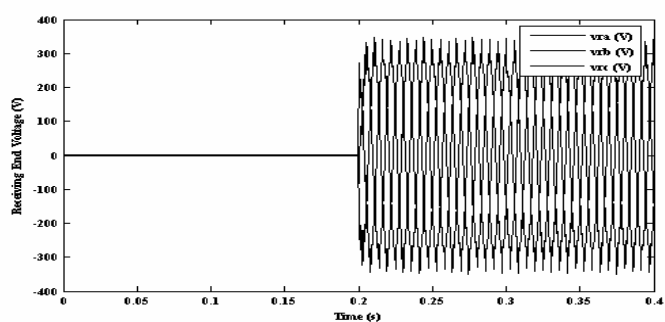

Fig. 17: Receiving End Voltage (V) with Conventional Controller

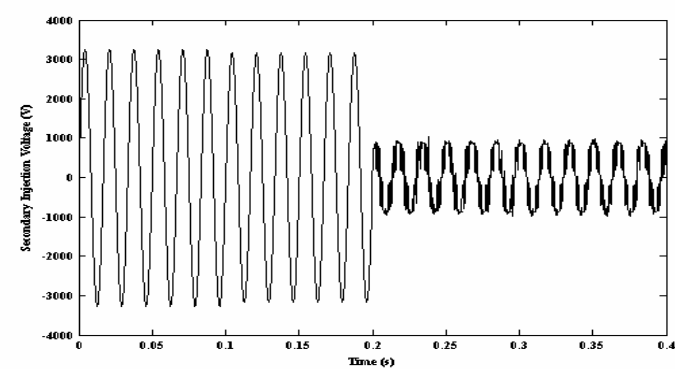

Fig. 18: Secondary Injection Voltage (V) with Conventional Controller

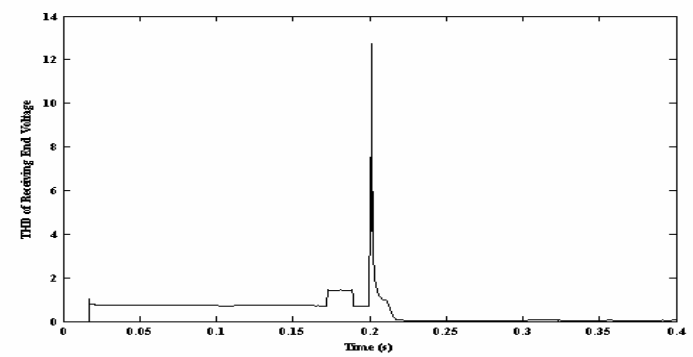

Fig. 19: THD of Receiving End Voltage with Conventional Control

The successful operation of DVR system for the elimination of voltage harmonics is illustrated in Fig. 17 and Fig. 19. Fig. 18 indicates the secondary voltage injection using conventional controllers. THD of source current $\left(\mathrm{I}_{\text {sthd }}\right)$, THD of load current $\left(\mathrm{I}_{\text {lthd }}\right)$, amplitude of source current (Ism), amplitude of load current $\left(\mathrm{I}_{\mathrm{lm}}\right)$, displacement power factor (DPF), THD of receiving end voltage $\left(\mathrm{V}_{\mathrm{rthd}}\right)$, the amplitude of the per phase receiving end voltage $\left(\mathrm{V}_{\mathrm{rm}}\right)$ and the phase angle of receiving end per phase voltage $\left(\mathrm{V}_{\mathrm{r} \varphi}\right)$ using $\mathrm{PI}$ controller in the shunt compensation circuit and NARMA-L2 controller and model reference controller in the series compensation circuit with different firing angles are tabulated in Table. 3- Table. 5. Table. 6 indicates the simulation results using FLC in 
the shunt compensation control circuit and conventional controller in the series control circuit.

\section{CONCLUSION}

An AI based UPQC system has been modeled using MATLAB toolbox. The novelty of this paper lies in the application of NNC algorithms such as MRC, and NARMA- L2 control to generate switching signals for the series compensator of the UPQC system. The performance of the system for applications such as voltage interruption, control of zero and negative sequence components, harmonic elimination and reactive power compensation has been successfully examined and analyzed. The implementation of MRC is more complex than that of NARMA-L2 controller for the same output performance.

\section{ACKNOWLEDGMENT}

The author is grateful to N. C. Sahoo, B. Venkatesh Abdulazeez S. Boujarwah, Christo George, K. S. Suresh Kumar, K. Padmakumari, K. P. Mohandas, and Ashok. S.

\section{REFERENCES}

1. Hirofumi Akagi, Trends in Active Power Line Conditioners, IEEE Tran. Power Electronics, vol. 9, no.3, May 1994, pp. 263-268.

2. Janko Nastran, Rafael Cajhen, Matija Seliger, and Peter Jereb, Active Power Filter for Nonlinear AC Loads, IEEE Trans. Power Electronics, vol.9, no.1, Jan. 1994, pp. 92-96.

3. E. Destobbeleer and L.Protin, On the Detection of Load Active Currents for Active Filter Control, IEEE Trans. Power Electronics, vol. 11, no.6, Nov. 1996, pp. 768-775.

4. Mauricio Aredes, Jurgen Hafner, and Klemens Heumann, Three-Phase Four-Wire Shunt Active Filter Control Strategies, IEEE Trans. Power Electronics, vol.12, no.2, Mar. 1997, pp. 311-318.

5. Hideaki Fujita and Hirofumi Akagi, The Unified Power Quality Conditioner: The Integration of Series- and Shunt-Active Filters, IEEE Tran. Power Electronics, vol. 13, no.2, Mar. 1998, pp. 315-322.

6. Fang Zheng Peng, George W. Ott Jr., and Donald J. Adams, Harmonic and Reactive Power Compensation Based on the Generalized Instantaneous Reactive Power Theory for ThreePhase Four-Wire Systems, IEEE Trans. Power Electronics, vol.13, no.6, Nov. 1998, pp. 11741181.
7. Kishore Chatterjee, B.G. Fernandes, and Gopal K. Dubey, An Instantaneous Reactive Volt-Ampere Compensator and Harmonic Suppressor System, IEEE Trans. Power Electronics, vol. 14, no.2, Mar. 1999, pp. 381-392.

8. Po-Tai Cheng, Subhashish Bhattacharya, and Deepak D. Divan, Line Harmonics Reduction in High-Power Systems Using Square-Wave Inverters-Based Dominant Harmonic Active Filter, IEEE Trans. Power Electronics, vol. 14, no.2, Mar. 1999, pp. 265-272.

9. Shyh-Jier Huang and Jinn-Chang $\mathrm{Wu}, \mathrm{A}$ Control Algorithm for Three-Phase Three-Wired Active Power Filters Under Nonideal Mains Voltages, IEEE Trans. Power Electronics, vol. 14, no. 4, Jul. 1999, pp. 753-760.

10. Ambrish Chandra, Bhim Singh, B.N.Singh, and Kamal Al-Haddad, An Improved Control Algorithm of Shunt Active Filter for Voltage Regulation, Harmonic Elimination, Power-factor Correction, and Balancing of Nonlinear loads, IEEE Trans. Power Electronics, vol. 15, no.3, May 2000, pp. 495-507.

11. Moleykutty George, Modeling and simulation of a current controlled three-phase shunt active power filter using MATLAB/PSB, AIUB Journal of Science and Engineering, vol. 3, no.1, Aug. 2004 issue, pp. 11-18.

12. M. George, C.L. Seen, Modeling and control of zero-sequence current of parallel three-phase converters using Matlab/power system blockset, IEEE Power Systems Conf. and Exp. 2004, PSCE 2004, vol. 3, pp. 1440-1443.

13. Hyosung Kim, Sang-Joon Lee, and Seung-Ki Sul, A calculation for the compensation voltages in dynamic voltage restorers by use of $\mathrm{PQR}$ power theory, 19th Annual IEEE Applied Power Electronics Conf. and Expo. 2004, APEC '04, vol. 1, pp. 573-579.

14. J. G. Nielsen, M. Newman, H. Nielsen, and F. Blaabjerg, Control and testing of a dynamic voltage restorer (DVR) at medium voltage level, IEEE Trans. on Power Electronics, vol. 19, issue 3, May 2004, pp. 806-813.

15. E. K. K. Sng, S. S. Choi, and D. M. Vilathgamuwa, Analysis of series compensation and DC-link voltage controls of a transformerless self-charging dynamic voltage restorer, IEEE Trans. Power Delivery, vol. 19, issue 3, Jul. 2004, pp. 15111518.

16. M. J. Newman, D. G. Holmes, J. G. Nielsen and F. Blaabjerg, A dynamic voltage restorer (DVR) with selective harmonic compensation at medium voltage level, IEEE Trans. Ind. Application, vol. 41, issue 6, Nov.-Dec. 2005, pp. 1744-1753. 
17. John Godsk Nielsen and Frede Blaabjerg, A detailed comparison of system topologies for dynamic voltage restorers, IEEE Trans. Ind. Applications, vol. 41, no.5, Sept. / Oct. 2005, pp. 1272-1280.

18. Leon M. Tolbert, Fang Zheng Peng, and Thomas G. Habetler, A multilevel converter-based universal power conditioner, IEEE Trans. Ind. Applications, vol. 36, no.2, Mar. / Apr. 2000, pp. 596-603.

19. Arindam Ghosh, and Gerard Ledwich, A unified power quality conditioner for simultaneous voltage and current compensation, Electric power systems research, vol. 59, 2001, pp. 55-63.

20. A. Elnady and M. M. A. Salama, New functionalities of the unified power quality conditioner, IEEE/PES Transmission and Distribution Conf. and Expo. 2001, vol. 1, 28 Oct.2 Nov. 2001, pp. 415-420.

21. R. Faranda and I. Valade, UPQC compensation strategy and design aimed at reducing losses, in Proc. 2002 IEEE Int. Symposium on Ind. Electronics, vol. 4, 8-11 Jul. 2002, pp. 1264-1270.

22. Gu Jianjun, Xu Dianguo, Liu Hankui, and Gong Maozhong, Unified power quality conditioner (UPQC): the principle, control and application, Proc. Power Conversion Conf. 2002, vol. 1, 2-5 Apr. 2002, pp. 80-85.

23. L. H. Tey, P. L. So, and Y. C. Chu, Neural network-controlled unified power quality conditioner for system harmonics compensation, Asia Pacific IEEE/PES Trans. and Distr. Conf. and Exhibition 2002, vol. 2, 6-10 Oct. 2002, pp. 10381043.

24. L. H. Tey, P. L. So, and Y. C. Chu, Unified power quality conditioner for improving power quality using ANN with hysteresis control, POWERCON 2004 Int. Conf. Power System Tech., Singapore, 21-24 Nov. 2004, vol. 2, pp. 1441-1446.

25. G. Chen, Y. Chen, L. F. Sanchez, and K. M. Smedley, Unified power quality conditioner for distribution system without reference calculations, 4th International Power Electronics and Motion Control Conf. 2004, IPEMC 2004, vol. 3, 14-16 Aug. 2004, pp. 1201-1206.

26. V. Khadkikar, P. Agarwal, A. Chandra, A. O. Barry, and T.D. Nguyen, A simple new control technique for unified power quality conditioner, 11 th Int. Conf. Harmonics and Quality of Power, 2004, pp. 289-293.
27. B. Han, B. Bae, H. Kim, and S. Baek, Combined operation of unified power-quality conditioner with distributed generation, IEEE Trans. Power Delivery, vol. 21, no.1, Jan. 2006,pp. 330 -338.

28. B. Venkatesh, M. K. George, H. B. Gooi, Fuzzy OPF incorporating UPFC, IEE Proc. Generation, Transmission and Distribution, vol. 151, issue 5, Sept. 2004, pp. 625-629.

29. Juan W. Dixon, Jose M. Contardo, and Luis A. Moran, A Fuzzy-controlled active front-end rectifier with current harmonic filtering characteristics and minimum sensing variables, IEEE Trans. Power Electronics, vol. 14, no.4, Jul. 1999, pp. 724-729.

30. H. L. Tan, N. A. Rahim, and W. P. Hew, A simplified fuzzy logic controller for dc series motor with improve performance, 2001 IEEE Int. Fuzzy Systems Conf., vol. 3, 2-5 Dec. 2001, pp. 15231526.

31. A. Elmitwally, M. S. Kandil, and M. Elkateb, A fuzzy-controlled versatile system for harmonics unbalance and voltage sag compensation, IEEE Power Engineering Society Summer Meeting, 1620 Jul. 2000, vol. 3, pp. 1439-1444.

32. A. Dell' Aquila, G. Delvino, M. Liserre, and P. Zanchetta, A new fuzzy logic strategy for active power filter, in Conf. publication no. 475, IEE Power Electronics and Variable Speed Drives, 1819 September 2000, pp. 392-397.

33. A. Dell' Aquila, A. Lecci,, M. Liserre, and P. Zanchetta, Design of the optimum duty cycle for a fuzzy controlled active filter, in Proc. 2000 IEEE Int. Symposium Ind. Electronics, vol. 1, 4-8 Dec. 2000, pp. 78-83.

34. S. K. Jain, P. Agarwal, and H. O. Gupta, Fuzzy logic controlled shunt active power filter for power quality improvement, IEE Proc. on Electrical power applications, vol. 149, no.5, Sept. 2002, pp. 317-328.

35. S. A. Farghal, M. S. Kandil, and Elmitwally, Evaluation of a shunt active power conditioner with a modified control scheme under nonperiodic conditions, IEE Proc. Generation, Transmission and Distribution, vol. 149, issue 6, Nov. 2002, pp. 726-732.

36. A. Dell'Aquila, A. Lecci, and M. Liserre, Microcontroller-based fuzzy logic active filter for selective harmonic compensation, Industry Applications Conf., 2003, 38th IAS Annual Meeting, Conf. Record, vol. 1, 12-16 Oct. 2003, pp. 285-292. 
37. Fan Shaosheng and Wang Yaonan, Fuzzy model predictive control for active power filter, Proc. IEEE Int. Conf. Electric Utility Deregulation, Restructuring and Power Technologies, vol. 1, 5-8 Apr. 2004, pp. 295-300.

38. Z. Lu and T. C. Green, Neural network based predictive control strategy of active power filter for electric drives, 7th Int. Conf. Power Electronics and Variable Speed Drives, publication no. 456, 21-23 Sept. 1998, pp. 287-291.

39. Wenxin Liu, G. K. Venayagamoorthy, and D. C. Wunsch II, Adaptive neural network based power system stabilizer design, in Proc. of the Int. Joint Conf. Neural Networks, 2003, vol. 4, 20-24 Jul. 2003, pp. 2970-2975.

40. S. D. Round and N. Mohan, Comparison of frequency and time domain neural network controllers for an active power filter, in Proc. of the Int. Conf. Ind. Electronics, Control, and Instrumentation, 1993, 15-19 Nov. 1993, vol.2, pp. 1099-1104.

41. Y. Karabag, T. Erfidan, S. Urgun, and N. Abut, Artificial neural network based hysteresis current controller for single-phase inverter, in Proc. of the 12th IEEE Mediterranean Electrotechnical Conf. 2004, vol. 1, 12-15 May 2004, pp. 339-341.

42. T. Kawagoshi, A. Kumamoto, T. Hikihara, Y. Hirane, K. Oku, O. Nakamura, S. Tada, K. Mizuki, and $\mathrm{Y}$. Inoue, $\mathrm{Y}$, Harmonic voltage suppression by active filter with neural network controller, in Proc. of the 2nd Int. Forum on Applications of Neural Networks to Power Systems, 1993, 19-22 Apr. 1993, pp. $93-98$.
43. A. Elmitwally, S. Abdelkader, and M. EI-Kateb, Neural network controlled three-phase four-wire shunt active power filter, IEE Proc. Generation, Transmission and Distribution , vol. 147, no. 2, Mar. 2000, pp. 87-92.

44. M.S. Kandil, S.A. Farghal, and A. Elmitwally, Multipurpose shunt active power conditioner, IEE Proc. Generation, Transmission and Distribution, vol. 149, no. 6, Nov. 2002, pp. 719-725.

45. J.R. Vazquez and P. Salmeron, Active power filter control using neural network technologies, IEE Proc. Power applications, vol. 150, no. 2, Mar. 2003, pp. 139-145.

46. M. G. Villalva and E. F. Ruppert, Current controller with artificial neural network for 3-phase 4-wire active filter, Power Electronics Specialists Conf. vol. 2, 20-25 Jun. 2004, pp. 993-998.

47. Patricio Salmeron and Jesus R. Vazquez, Practical design of a three-phase active power-line conditioner controlled by artificial neural networks, IEEE Trans. Power Delivery, vol. 20, no. 2, Apr. 2005, pp. 1037-1044.

48. G. Tsirigotis, D. Bandekas, D. Pogaridis, J. L. Lizaro, Comparative control of a nonlinear first order velocity system by a neural network NARMA-L2 method, Electronics and Electrical Eng., T 170 Electronics, ISSN 1392-1215, pp. 5-8.

49. S. Motamarri, H. A. Malki, Exercise Machine Controller Design, ISMCR2004, B21, pp. 1-7. 